\title{
KONSTRUKSI PEMBERITAAN KASUS BODY SHAMING ARTIS DIAN NITAMI DI NAKITA.GRID.ID DAN TEMPO.CO
}

\author{
Anggun Putri Dewanggi I.B, Laksmi Rachmaria \\ anggun.putridewanggi@budiluhur.ac.id; laksmi.ozil@gmail.com \\ Universitas Budi Luhur
}

\begin{abstract}
Body shaming is an act of mocking or insulting by commenting on a person's physical form or body size. Body shaming is synonymous with bullying behavior, because it will affect one's self-image, self-concept, and self-confidence. This study aims to see how the construction of body shaming reports that hit Dian Nitami artists in Tempo.Co and Nakita.Id online media. The research approach used in this study is qualitative with a constructivist paradigm. This study uses Robert N. Entman's Framing Theory. Research results: Tempo.Co in its frame brings the case of bullying that befell Dian Nitami artists to the realm of law.Tempo.Co positions the account@corissa.putrie owner as the cause of the problem and Anjasmara as a hero. Make Moral Judgment which is presented by Tempo.Co in the news in the form of a threat of punishment that will be accepted by the body shaming perpetrators on social media. Treatment Recommendation offered by Tempo. Co in its news text so that people are wiser and wiser in speaking on social media. Nakita.Id brought this case to the moral realm. Nakita.Id positioned the@corissa.putrie account and also the women who use social media as the cause of the problem, Anjasmara is positioned as Dian Nitami's hero and artist as a victim. The Make Moral Judgment presented by Nakita.Id was an appeal to reflect on what we had typed with the fingers and uploaded to the internet. Treatment Recommendations are offered so that every citizen takes heed of ethics in social media. Conclusion: media is a means for people to understand various realities. through the construction of news reporters display and place events in a particular social context where the audience is.
\end{abstract}

Keyword: Construction, News, Body Shaming

\begin{abstract}
ABSTRAK
Body shaming merupakan tindakan mengejek atau menghina dengan memberi komentar terhadap bentuk fisik ataupun ukuran tubuh seseorang. Body shaming identik dengan perilaku bullying, karena akan berpengaruh terhadap citra diri, konsep diri, dan rasa percaya diri seseorang. Penelitian ini bertujuan untuk melihat bagaimana konstruksi pemberitaan kasus body shaming yang menimpa artis Dian Nitami di media online Tempo.Co dan Nakita.Id. Pendekatan penelitian yang digunakan pada penelitian ini adalah kualitatif dengan paradigma konstruktivis. Penelitian ini menggunakan Teori Framing Robert N. Entman. Hasil penelitian Tempo.Co dalam bingkainya membawa kasus bullying yang menimpa artis Dian Nitami ke ranah hukum. Tempo.Co memosisikan pemilik akun@corissa.putrie sebagai penyebab masalah dan Anjasmara sebagai pahlawan. Make Moral Judgement yang ditampilkan Tempo.Co dalam beritanya berupa ancaman hukuman yang akan diterima pelaku body shaming di media sosial. Treatment Recommendation yang ditawarkan Tempo.Co dalam teks beritanya agar masyarakat lebih arif dan bijaksana dalam bertutur kata di sosial media. Nakita.Id membawa kasus ini ke ranah moral. Nakita.Id memosisikan akun @ corissa.putrie dan juga para wanita pengguna media sosial sebagai penyebab masalah, Anjasmara diposisikan sebagai pahlawan dan artis Dian Nitami sebagai korban. Make Moral Judgement yang ditampilkan Nakita.Id berupa himbauan untuk merenungkan apa yang pernah kita ketik dengan jarijari dan diunggah ke internet. Treatment Recommendation yang ditawarkan agar setiap warganet mengindahkan etika dalam bermedia sosial. Simpulan media merupakan sarana bagi masyarakat dalam memahami berbagai realitas. Melalui konstruksi beritanya wartawan menampilkan sekaligus menempatkan peristiwa dalam konteks sosial tertentu di mana khalayak itu berada.
\end{abstract}




\section{PENDAHULUAN}

Jempol netizen memang tidak bisa diatur. Masyarakat suka sekali dengan seenaknya memberikan komentar kepada orang lain sesuka hati melalui media sosial. Kali ini salah satu korban yang mendapatkan komentar pedas dari netizen adalah aktris senior Dian Nitami (Tarigan, 2018). Persoalan bermula saat unggahan foto Dian Nitami di Instagram justru mendapatkan cibiran dari seorang warganet (netizen) dengan akun Instagram (a)corissa.putrie. Warganet tersebut memberikan komentar atas unggahan foto Dian Nitami seputar fisik sang aktris.

"Itu hidungnya jelek banget, melar banget, jempol kaki juga bisa masuk. Waduh operasi lah..katanya artis, masa duit buat perbaiki hidung gak ada...waduh," ujar warganet tersebut (Daruwati, 2018).

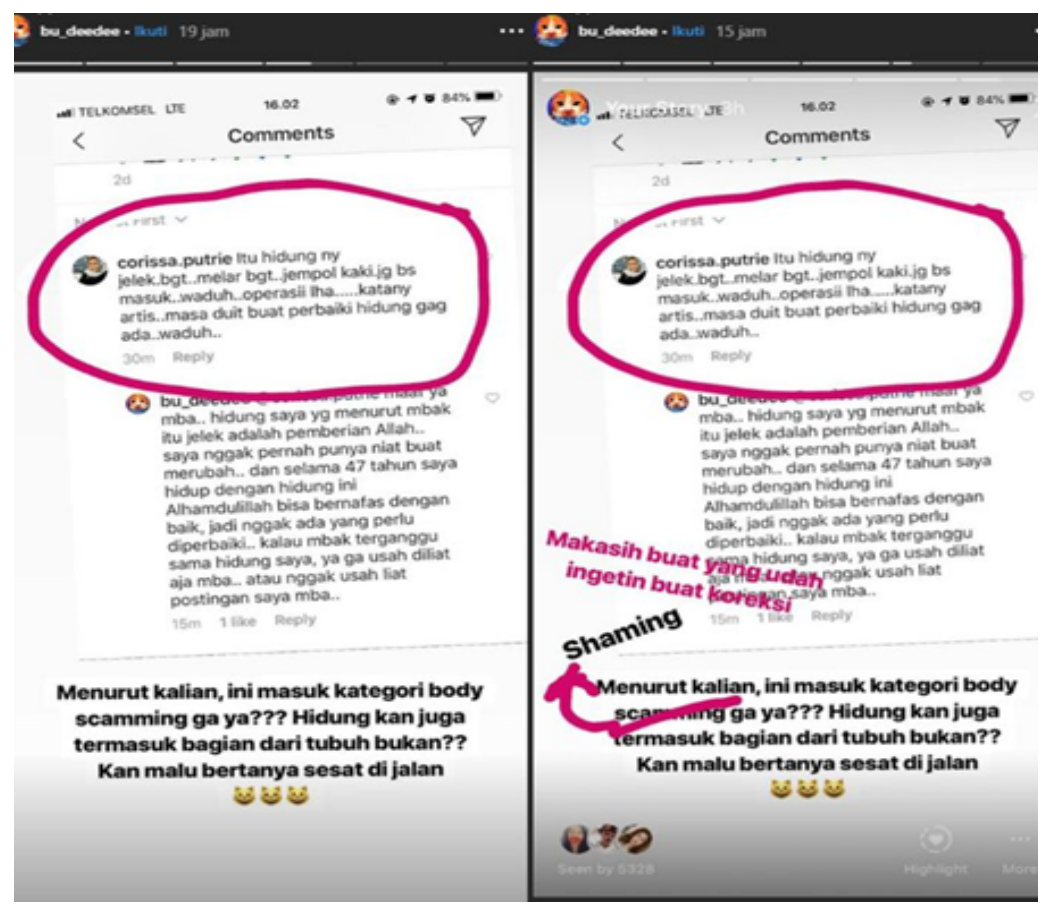

Gambar 1 Screenshoot Instagram Artis Dian Nitami

$\mathrm{Pe}$

shaming

sampai d

ari 2019

aktris I

varganet

melaporkan perilaku buruk warganet tersebut ke polisi karena dianggap

yang menghina fisik istrinya ke Polres Metro Jakarta Selatan. 
Body shaming adalah istilah yang merujuk pada kegiatan mengkritik dan mengomentari secara negatif fisik atau tubuh sendiri maupun orang lain (Pahlawani, 2018). Vargas (dalam Chairani, 2018) mengungkapkan ciri-ciri perilaku body shaming diantaranya: 1) Mengkritik penampilan sendiri, melalui penilaian atau perbandingan dengan orang lain. 2) Mengkritik penampilan orang lain di depan mereka. 3) Mengkritik penampilan orang lain tanpa sepengetahuan mereka.

Lebih lanjut Fredrickson mengungkapkan Rasa malu pada tubuh adalah konsep yang menunjukkan adanya kesadaran diri dan juga respon negatif terhadap diri sendiri. Hal ini menjadi suatu langkah salah untuk memenuhi standar tubuh ideal, dan pengakuan atas kegagalan memenuhi standar (Chairani, 2018). Dalam hal ini selebriti merupakan kelompok yang rawan terkena body shaming, mereka dituntut untuk selalu sempurna dalam setiap penampilannya.

Tidak hanya Dian Nitami, selebriti Indonesia yang mengalami kasus body shaming diantaranya Tasya Kamila, Prilly Latuconsina, Putri Titian dan Audi Item yang dikomentari "gendut" oleh warganet, misalnya. Memiliki tubuh kurus pun tidak berarti bebas dari ancaman body shaming, artis Eva Celia pun sering dikomentari "terlalu kurus".
Penelitian yang dilakukan

oleh Departement of Medical Psychology and Medical Sociology University of Leipzig, Jerman mengungkapkan adanya kaitan antara body shaming dengan keinginan bunuh diri. Riset tersebut mengungkapkan bahwa perempuan fat shaming lebih rentan terhadap resiko percobaan bunuh diri (Tarigan, 2018).

Media adalah tempat di mana khalayak memperoleh informasi mengenai realitas politik dan sosial yang terjadi di sekitar mereka (Eriyanto, 2012). Oleh karena itu, penafsiran individu atas sebuah peristiwa dipengaruhi oleh bagaimana media membingkai peristiwa tersebut. Pemahaman individu atas realitas politik dan sosial terbentuk dari apa yang disajikan oleh media.

Selain fungsi menyampaikan informasi, pers juga memiliki fungsi mendidik/edukasi. Dalam hal ini pers merupakan saluran yang efektif dalam melakukan pendidikan sosial, politik, moral, dan berbagai arti kehidupan lainnya secara massal (Asep Saeful Muhtadi, 1999). Body shaming identik dengan bullying, karena akan berpengaruh terhadap citra diri, konsep diri, dan rasa percaya diri seseorang. Menjadi korban body shaming sangat mungkin menyebabkan seseorang mengalami gangguan mental, sehingga mereka bisa saja melakukan aktivitas yang dapat menyakiti dirinya sendiri 
dengan sengaja. Terkait hal tersebut dalam hal ini pers berusaha untuk mencoba tidak hanya sekadar mencatat dan melaporkan peristiwa, tetapi juga memaknai peristiwa/fenomena yang ada sekaligus mendidik masyarakat tentang bagaimana bermedia sosial secara bijak.

Kasus body shaming yang menimpa aktris Senior Dian Nitami dari sisi jurnalistik memiliki nilai berita konflik, prominence, human interest, impact (akibat), informasi, dan aktual (pada saat itu). Melalui portal berita Nakita.grid.id dan Tempo.Co peneliti mencoba untuk melihat bagaimana peristiwa body shaming yang menimpa aktris Dian Nitami diceritakan (dikonstruksi) dalam setiap pemberitaannya. Di sini media berperan bagaimana sebuah realitas didefinisikan oleh media dengan cara-cara tertentu seperti lewat kata, kalimat ataupun gambar. Sebagai acuan teoritis berkaitan dengan peran media, Joseph $\mathrm{R}$. Dominic mengungkapkan setidaknya ada 5 fungsi komunikasi massa, yaitu:

Pengawasan (Surveillance). Surveillance mengacu kepada yang kita kenal sebagai peranan berita dan informasi dari media massa. Fungsi pengawasan ini dibagi dua, yaitu pengawasan peringatan (media menyampaikan informasi kepada kita mengenai ancaman topan, letusan gunung api, kondisi ekonomi yang mengalami depresi, meningkatnya inflasi, atau serangan militer), dan pengawasan instrumental (berkaitan dengan penyebaran informasi yang berguna bagi kehidupan sehari-hari).

Interpretasi (Interpretation). Media massa tidak hanya menyajikan fakta dan data, tetapi juga informasi beserta interpretasi mengenai suatu peristiwa. Contoh paling nyata dari fungsi interpretasi adalah tajuk rencana surat kabar dan komentar radio atau televisi siaran. Interpretasi ini acap kali mendapat perhatian utama para pejabat pemerintah, tokoh politik, dan pemuka masyarakat karena sering bersifat kritik terhadap kebijaksanaan pemerintah.

Hubungan (Linkage). Media massa mampu menghubungkan unsur-unsur yang terdapat di dalam masyarakat yang tidak bisa dilakukan secara langsung oleh saluran perseorangan. Fungsi hubungan yang dimiliki media itu sedemikian berpengaruhnya kepada masyarakat sehingga dijuluki "public making" ability of the mass media atau kemampuan membuat sesuatu menjadi umum dari media massa.

Sosialisasi, Bagi Dominick, sosialisasi merupakan transmisi nilai-nilai (transmission of values) yang mengacu kepada cara-cara di mana seseorang mengadopsi perilaku dan nilai-nilai dari suatu kelompok.

Hiburan (Entertainment). Bagi Dominick, hiburan merupakan fungsi media 
massa. Mengenai hal ini memang jelas tampak pada televisi, film, dan rekaman suara (Effendy Uchjana, 2013).

Analisis framing merupakan salah satu metode analisis teks yang berada dalam kategori penelitian konstruksionis. Paradigma ini memandang realitas kehidupan sosial bukanlah realitas yang natural, tetapi hasil dari konstruksi (Eriyanto, 2012). Dalam pandangan konstruksionis berita diibaratkan seperti sebuah drama dimana terjadi pertarungan antara berbagai pihak yang berkaitan dengan sebuah peristiwa. Sebagaimana sebuah drama, tentu saja ada pihak yang didefinisikan sebagai pahlawan, tetapi ada juga pihak yang didefinisikan sebagai musuh dan pecundang (Eriyanto, 2012).

Lebih lanjut mengenai framing (pembingkaian berita) dan ideologi, saat memproduksi sebuah berita ada dua hal yang menjadi rujukan para wartawan. Pertama, praktik organisasi dan ideologi dimana dalam hal ini berhubungan dengan rutinitas yang terjadi di ruang pemberitaan, yang menentukan bagaimana wartawan dikontrol untuk memberitakan sebuah peristiwa dalam perspektif tertentu. Kedua, aspek konstruksi sosial, yakni bagaimana peristiwa tersebut ditempatkan dalam keseluruhan produksi teks, bagaimana berita tersebut dapat bermakna bagi khalayak.

Entman melihat framing dalam dua dimensi besar: seleksi isu dan penonjolan aspek. Dalam konsep Entman, framing pada dasarnya merujuk pada pemberian definisi, penjelasan, evaluasi dan rekomendasi dalam suatu wacana untuk menekankan kerangka berfikir tertentu terhadap peristiwa yang diwacanakan.

Konsep framing dari Entman tersebut menggambarkan secara luas bagaimana sebuah peristiwa dimaknai atau ditandakan oleh wartawan. Entman membagi perangkat framing ke dalam empat elemen sebagai berikut:

Define Problem (pendefinisian masalah), elemen ini merupakan master frame/bingkai yang paling utama. Ia menekankan bagaimana peristiwa dipahami oleh wartawan. Peristiwa yang sama bisa dipahami dengan cara dan bingkai yang berbeda.

Diagnose

Causes (memperkirakan penyebab masalah), merupakan elemen framing untuk membingkai siapa saja yang dianggap aktor dari suatu peristiwa. Penyebab di sini bisa what (apa) atau who (siapa).

Make Moral Judgement (membuat keputusan moral) adalah elemen framing yang dipakai untuk membenarkan/memberi argumentasi pada 
pendefinisian masalah yang sudah dibuat.

Treatment Recommendation (menekankan penyelesaian masalah), elemen ini dipakai untuk menilai apa yang dikehendaki oleh wartawan. Jalan apa yang dipilih untuk menyelesaikan masalah. Penyelesaian massalah itu tentu saja sangat tergantung pada bagaimana peristiwa itu dilihat dan siapa saja yang dipandang sebagai penyebab masalah (Eriyanto, 2012).

Pembuatan berita di media pada dasarnya adalah penyusunan realitas-realitas hingga membentuk suatu realitas atau wacana yang bermakna. Dengan demikian, seluruh isi media tiada lain adalah realitas yang telah dikonstruksikan (constructed reality) dalam bentuk wacana yang bermakna (Hamad, 2004).

Adapun sebuah konstruksi realitas mempunyai prinsip setiap upaya "menceritakan"

(konseptualisasi) sebuah peristiwa, keadaan, atau benda adalah usaha mengonstruksikan realitas. Karena sifat dan faktanya bahwa pekerjaan media massa adalah menceritakan peristiwa-peristiwa, maka kesibukan utama media massa adalah mengkonstruksikan berbagai realitas yang akan disiarkan. Media menyusun realitas dari berbagai peristiwa

Aspek konstruksi ini berhubungan dengan bagaimana wartawan/media menampilkan peristiwa tersebut sehingga relevan bagi khalayak dan ditempatkan dalam konteks sosial tertentu dimana khalayak tersebut berada (Eriyanto, 2012). Media di sini berupaya untuk menjaga nilai-nilai kelompok, dan melakukan kontrol agar nilai-nilai kelompok itu dijalankan, sehingga membentuk kenyataan apa yang layak, apa yang baik, apa yang sesuai, dan apa yang dipandang menyimpang.

\section{METODE PENELITIAN}

Penelitian ini menggunakan pendekatan kualitatif dengan metode analisis framing Robert N. Entman. Pendekatan kualitatif bertujuan untuk mendapatkan data-data deskriptif melalui kata-kata maupun kalimat. Penelitian kualitatif menekankan realitas yang dibangun secara sosial, hubungan yang intim antara peneliti dengan yang dipelajari membentuk penyelidikan (Salim, 2001).

Paradigma yang digunakan pada penelitian ini adalah konstruktivisme. Paradigma konstruktivisme memandang realitas kehidupan sosial bukanlah realitas yang natural, melainkan hasil dari konstruksi (Eriyanto, 2012).

Pendekatan kualitatif menurut Rachmat Kriyantono merupakan pendekatan yang bertujuan menjelaskan fenomena-fenomena yang sedalam-dalamnya melalui pengumpulan data yang selengkaplengkapnya. Riset ini tidak 
mengutamakan besarnya populasi sampling (Kriyantono, 2006).

Analisis Framing sebagai sebuah metode analisis teks, framing mempunyai karakteristik yang berbeda dibandingkan dengan analisis isi kuantitatif. Dalam analisis isi kuantitatif, yang ditekankan adalah isi (content) dari suatau pesan/teks komunikasi. Sementara dalam analisis framing, yang menjadi pusat perhatian adalah pembentukan pesan dari teks. Framing, terutama, melihat bagaimana pesan/peristiwa dikonstruksi oleh media (Eriyanto, 2012).

\section{HASIL DAN PEMBAHASAN}

\section{A. Framing Tempo.Co}

\section{Define}

\section{Problem}

(Pendefinisian Masalah). Terkait kasus body shaming yang menimpa aktris Dian Nitami Tempo.Co mengidentifikasikan peristiwa tersebut ke ranah hukum. Hal ini dibuktikan dengan narasumber yang diwawancarai oleh Tempo.Co adalah orang-orang yang berlatar belakang hukum, atau kalaupun bukan orang yang berlatar belakang hukum (ahli hukum atau pengacara), tetapi narasumber tersebut berbicara dalam kerangka masalah hukum. Tempo.Co pada kasus body shaming yang menimpa artis Dian Nitami mewawancarai Kepala Kepolisian Resor Jakarta Selatan, Komisaris Besar Indra Jafar.

Body shaming merupakan tindakan mengejek/menghina dengan mengomentari fisik baik itu bentuk ataupun ukuran tubuh seseorang. Penghinaan yang dilakukan melalui media sosial merupakan tindak pidana di mana pelakunya dapat dijerat Undang-Undang Nomor 11 Tentang Informasi dan Transaksi Elektronik pasal 27 ayat (3) UndangUndang ITE yang berbunyi sebagai berikut: setiap orang dengan sengaja dan tanpa hak mendistribusikan dan/ atau mentransmisikan dan/atau membuat dapat diaksesnya Informasi Elektronik dan/atau Dokumen Elektronik yang memiliki muatan penghinaan dan/atau pencemaran nama baik sebagaimana dimaksud dalam Pasal 27 ayat (3) UU ITE dipidana dengan penjara paling lama 4 (empat) tahun dan/atau denda paling banyak Rp. 750 juta.

\section{Diagnose Causes (Penyebab}

Masalah). Ada 2 aktor secara eksplisit ditampilkan pada kasus ini. Dari keseluruhan berita yang diangkat Tempo.Co, Tempo.Co memosisikan pemilik akun Instagram (a)carissa.putrie sebagai penyebab masalah yang dapat terlihat dari kutipan berita berikut ini:

Aktris Dian Nitami alami body shaming oleh netizen. Sebuah akun media sosial mengomentari tentang hidung Dian Nitami yang dinilai akun itu besar. Akun itu pun menyarankan agar Dian melakukan operasi. "itu hidungnya jelek banget, melar banget, jempol kaki juga bisa masuk. Waduh, operasi lah. 
Katanya artis, masa duit buat perbaiki hidung enggak ada," komentar sebuah akun pada Instagram Dian Nitami, Jum'at 28 Desember 2018 (Tarigan, 2018).

Untuk memperkuat bingkainya Tempo.Co juga menampilkan komentar Anjasmara selaku suami aktris Dian Nitami: "Kok istriku dibilang jelek sama kamu. Aku aja enggak pernah bilang kalau istriku itu jelek. Aku justru senang kalau Istriku apa adanya, “ tulis Anjasmara. (Tarigan, 2018).

Di sini sudah mulai terlihat bagaimana pemilik akun Instagram (a)corissa.putrie ditempatkan dalam keseluruhan berita sebagai penyebab masalah. Tempo. Co melalui narasi beritanya mengungkapkan bahwa body shaming yang dilakukan oleh pemilik akun Instagram @ corissa.putrie tergolong kepada tindakan bullying karena akan berpengaruh pada citra diri, konsep diri, dan rasa percaya diri seseorang. ...seseorang yang merasa terlalu tidak percaya diri akan cenderung haus pengakuan. Prestasi didapatkan hanya untuk memenuhi hasrat atau kebutuhan pengakuan yang tinggi..bahaya lainnya, perasaan inferior akibat body shaming bisa membuat seseorang menjadi permisif terhadap kekerasan yang menimpanya. Dia akhirnya jadi rentan menjadi korban kekerasan. Sebab, dalam pikiran si korban telanjur tertanam anggapan bahwa dirinya tidak layak. (Tarigan, 2018).

Tempo.Co mencoba melakukan penonjolan aspek berupa kata, kalimat ataupun gambar. Tempo.Co menggunakan kata-kata atau frasa seperti tidak percaya diri, haus pengakuan, bahaya, korban, perasaan inferior, body shaming, permisif, rentan, korban kekerasan, dirinya tidak layak untuk memperkuat bingkainya tentang dampak dan bahaya dari melakukan body shaming.

Selain memosisikan pemilik akun Instagram @corissa.putrie sebagai penyebab masalah, Tempo.Co juga menempatkan Anjasmara sebagai pahlawan. Hal ini dapat dilihat dari teks berita berikut ini:

...melihat sang istri dicela, Anjasmara pun berusaha membelanya...Pria yang juga instruktur Yoga itu mengatakan justru merasa lebih senang bila sang istri berdandan apa adanya. "kecantikan yang terpenting buat saya dari hati, sikap dan bicaranya. Bukan dari tampak luar dengan hidung mancung, tubuh sexy dan polesan make up yang tebal," kata Anjasmara. (Tarigan, 2018).

...melihat istrinya dihina di sosial media, Anjasmara tak tinggal diam. Dia langsung menindaklanjuti lewat jalur hukum. Sebelumnya 
Anjasmara sempat memberi peringatan lewat akun Instagram pribadinya. Dia meminta Corissa Putrie meminta maaf di media sosial dan surat kabar nasional satu halaman penuh (Nurhayati, 2019).

Tempo.Co menampilkan sosok Anjasmara sebagai suami yang dengan sigap membela dan mendukung istrinya saat sang istri mengalami hinaan atas bentuk tubuhnya di media sosial. Lebih lanjut Tempo.Co dalam narasi beritanya juga memuat dukungan dari para netizen, termasuk para rekan sesama artis.

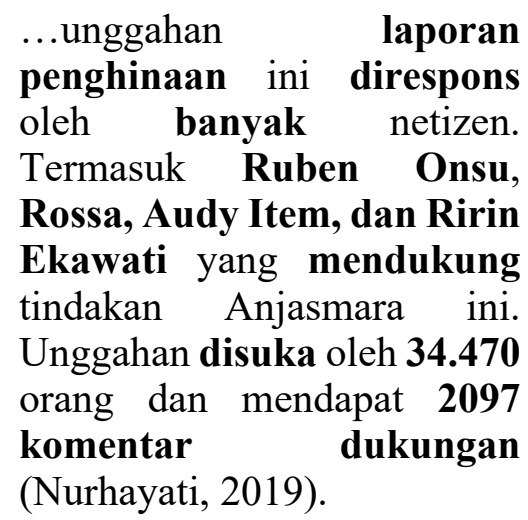

Tempo.Co menggunakan kata-kata laporan, penghinaan, direspons, banyak, Ruben Onsu, Rossa, Audy Item, Ririn Ekawati untuk mempertegas bingkainya. Tempo juga menonjolkan angka 34.470 dan 2097 untuk semakin memperkuat bingkai bahwa pelaku body shaming harus diberi tindakan yang tegas.

Make Moral Judgement (Keputusan Moral). Tempo.Co memuat penilaian atas Corissa Putrie sebagai penyebab masalah didasari oleh pertama dampak psikologis dari korban body shaming. Kedua, dengan mengutip pernyataan Kepala Kepolisian Resor Jakarta Selatan, Komisaris Besar Indra Jafar bahwa kegiatan melakukan body shaming merupakan aktivitas yang melanggar hukum. Hal ini terlihat pada teks berita berikut:

Kepala Kepolisian Resor Jakarta Selatan, Komisaris Besar Indra Jafar mengatakan, pelaku pelanggaran UndangUndang Informasi dan Transaksi Elektronik (UU ITE) atau Undang-Undang nomor 11 tahun 2008 dapat terancam hukuman penjara selama enam tahun. "itu maksimalnya, kalau terbukti melanggar," kata dia saat dihubungi Tempo, Kamis, jika terbukti melanggar, pelaku akan dikenakan UU ITE pasal 45 ayat 1 dan pasal 27 ayat 3 , dengan ancaman maksimal hukuman enam tahun penjara. Hingga saat ini, kata Indra, kasus ini masih dalam tahap pemeriksaan (Tarigan, 2018).

Treatment Recommendation (Penyelesaian Masalah). Tempo.Co merekomendasikan agar masyarakat lebih arif dan bijaksana dalam bertutur kata di sosial media, karena saat ini sudah ada sanksi hukumnya.

B. Framing Nakita.Grid.Id 


\section{Define}

Problem

(Pendefinisian Masalah). Berbeda dengan redaksi Tempo.Co, redaksi Nakita.id membawa kasus body shaming yang menimpa aktris senior Dian Nitami ke ranah moral. Nakita.id menghadirkan narasumber diantaranya Dosen Komunikasi Media Birmingham City University, Dave Harte, Kepala Peneliti Microsoft Research, Danah Boyd. Nakita.id juga mengutip kutipan sebuah akun kesehatan di Instagram @ thistemporary.

Redaksi

Nakita.id

mengungkapkan bahwa di zaman serba online seperti saat ini komentarkomentar warganet bukanlah hal yang baru di ranah media sosial, baik di kalangan artis maupun masyarakat biasa. Kemudahan internet membuat orang berani berkomentar apapun secara online.

Redaksi Nakita.id menjadikan komentar Dave Harte, Dosen Komunikasi Media Birmingham City University sebagai salah satu rujukan dalam teks berita berikut ini:

Dosen Komunikasi Media Birmingham City University, Dave Harte, memaparkan jika diskusi di Internet memberikan kesempatan untuk mengucapkan hal-hal yang tak mungkin diungkap ketika bertatap muka. Akibatnya, diskusi-diskusi di internet kerap berakhir kisruh. Bahkan kelompok yang awalnya berkumpul karena kesamaan hobby bisa terpecah-belah..

(Anisa Annan, 2019).

Lebih lanjut, senada dengan apa yang diungkapkan Dave Harte, Nakita.id juga menampilkan komentar dari Danah Boyd, Kepala Peneliti Microsoft Research. Boyd mengungkapkan keprihatinannya atas apa yang tejadi di media sosial, yakni maraknya komentar negatif di internet. Nakita.id melakukan penonjolan dalam bentuk kata-kata ataupun kalimat seperti kisruh, terpecah belah, berkomentar jahat pada orang lain dan dirinya sendiri, hujatan, komentar pedas, fisik, menghujat hidung, jelek, operasi hidup, melar banget, jelek banget, jempol kaki juga bisa masuk, gak ada duit, perbaiki hidung.

Setelah beberapa tahun,
internet berkembang dari
subkultur menjadi hal yang
mainstream, saya melihat
wanita-wanita muda kembali
menggunakan internet untuk
berkomentar jahat pada
orang lain dan dirinya
sendiri. Ini menghancurkan
hati saya (Anisa Annan,
2019 ).

Diagnose Causes (Penyebab Masalah). Dalam keseluruhan teks berita, seperti Tempo.Co, redaksi Nakita.grid.id juga memosisikan pemilik akun Instagram @ carissa.putrie sebagai penyebab masalah karena menghina fisik Dian Nitami.

Meski hanya dengan kaus sederhana, Dian Nitami tetap 
terlihat cantik awet muda. Namun, foto cantik Dian ini justru mendapatkan hujatan dari salah seorang warganet, Moms. Warganet tersebut memberikan komentar pedas mengenai fisik Dian Nitami, terutama bagian hidung. Ia menghujat hidung Dian yang dianggapnya jelek dan menyuruh Dian untuk melakukan operasi hidung.

"itu hidungnya jelek banget..melar

banget..jempol kaki juga bisa masuk..waduh..operasi lha..katanya artis..masa duit buat perbaiki hidung gag ada..waduh, " ujar warganer tersebut

(Daruwati, 2018).
Instagram Dian Nitami yang berisi komentar negatif dari warganet tersebut.

Bahwa apa yang dilakukan oleh Carissa Putrie adalah sesuatu yang tidak pantas merupakan bingkai yang hendak dibuat oleh redaksi Nakita.id. Ada kata-kata "nyakitin hati", frasa "saya punya waktu yang cukup lama untuk bikin istri saya PD (Percaya Diri), "kamu hancurin gitu aja", dan "enak banget". Nakita.id juga memuat pernyataan Anjasmara terkait kasus body shaming yang menimpa istrinya dalam teks berikut:

Redaksi Nakita.grid.id juga memuat gambar screenshoot akun

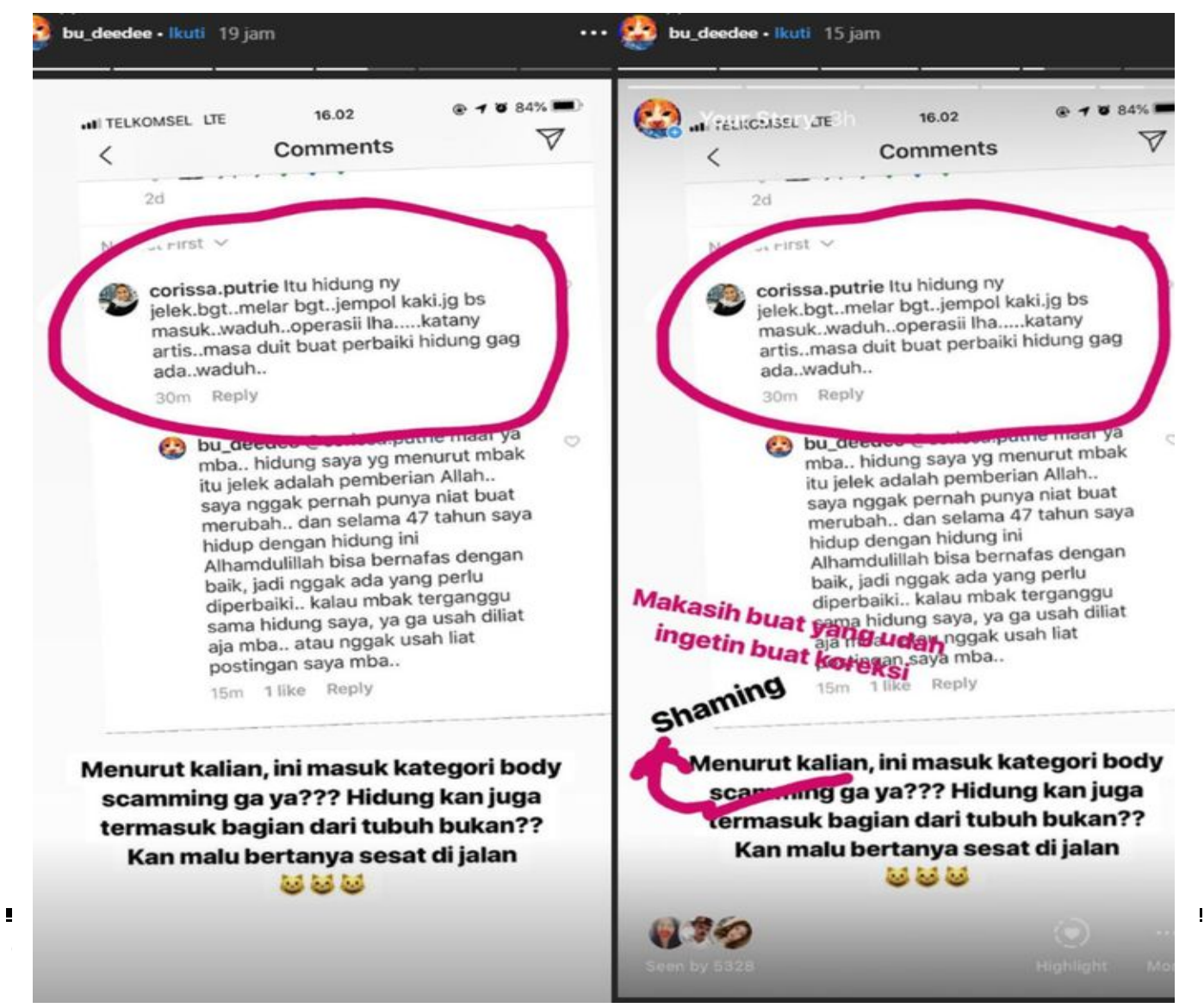

Gambar 2 Komentar @corissa.putrie Atas Unggahan Foto Dian Nitami di Instagram 
"Kamu tahu enggak kamu udah nyakitin hati istri saya? Kamu tahu enggak saya punya waktu yang cukup lama untuk bikin istri saya PD (Percaya Diri)? Sekarang kamu hancurin gitu aja, terus kamu minta maaf gitu aja, enak banget," lanjutnya (Diah Puspita Ningrum, 2018).

Paragraf selanjutnya pun, masih di judul berita yang sama, redaksi Nakita.grid.id memperkuat bingkainya bahwa apa yang dilakukan oleh Carissa Putrie adalah sesuatu yang sudah melewati batas.

Aktor berumur 43 tahun ini juga mengaku sebenarnya ia tidak ingin terlibat masalah dengan siapapun. Namun, tindakan warganet yang melakukan body shaming kepada istrinya itu ia nilai sudah melewati batas. Ia merasa tidak adil bila pelaku bully dilepaskan begitu saja karena sudah mengucapkan permintaan maaf.

Redaksi Nakita.id juga memosisikan Anjasmara sebagai pahlawan, karena apa yang dilakukan Anjas selain sebagai tanggung jawabnya sebagai suami yang melindungi istri, Anjasmara juga dianggap sebagai orang yang ikut memerangi cyber bullying. Tak hanya rekan-rekan sesama selebriti, warganet lainnya juga ikut memberikan dukungannya pada Anjasmara, Moms. Mereka memberikan dukungan pada Anjasmara untuk memerangi cyber bullying yang menimpa istrinya itu.

Sebenarnya malas ngurusin kayak ginian. Tapi Istri saya dibully. Kalau saya yang dibully mah saya diemin aja. Harusnya sih enggak ada masalah ya kalau kita bisa memberikan komentarkomentar yang membangun (Diah Puspita Ningrum, 2018).

Redaksi Nakita.id secara eksplisit menempatkan aktris Dian Nitami sebagai korban hal ini terlihat dari teks berita berikut ini:

Komentar pedas warganet itupun kemudian dibalas dengan bijak oleh ibu dua anak ini. " Maaf ya mba.. hidung saya yang menurut mbak jelek itu adalah pemberian Allah...saya nggak pernah punya niat untuk merubah..dan selama 47 tahun saya hidup dengan hidung ini, Alhamdulillah bisa bernafas dengan baik, jadi nggak ada yang perlu diperbaiki. Kalau mbak 
merasa terganggu sama hidung saya, ya ga usah diliat aja mba. Atau nggak usah liat postingan saya mba,' jawab Dian Nitami dengan sabar (Daruwati, 2018).

Selain pemilik akun instragram@carissa.putrie, Nakita.id juga menempatkan para wanita pengguna media sosial juga sebagai penyebab masalah terjadinya kasus body shaming.

Wanita mencari inspirasi kecantikan di media sosial, padahal penggambaran di sana dirasa tidak realistis. Media sosial diibaratkan sebagai kehidupan buatan, di mana penggunanya mengunggah konten yang dibuat sedemikian rupa sehingga memenuhi standar yang diinginkan. Standar itu terbentuk dari media sosial sendiri. Komentar-komentar warganet tentu turut andil membentuk seperti apa sesuatu yang ideal, termasuk bentuk tubuh. (Anisa Annan, 2019).

Ketidakpuasan individu akan tubuhnya sendiri semakin menguat apabila individu tersebut menerima penilaian yang disampaikan melalui media sosial tentang seperti apa tubuh yang ideal.

Semakin banyak wanita yang mencari inspirasi kecantikan melalui Instagram atau tutorial make up di YouTube. Namun sebuah penelitian yang dilakukan perusahaan Dove Beauty membuktikan lebih dari 75 persen responden menyatakan cara media sosial menggambarkan seorang wanita tampak tidak realistis. Akan tetapi, dengan terus berkembangnya pengguna media sosial, maka semakin banyak wanita yang akan terpengaruh oleh gambarangambaran online itu (Anisa Annan, 2019).

Lebih lanjut redaksi Nakita.grid.id juga menyertakan data riset untuk memperkuat bingkai beritanya:

Riset membuktikan jika
pengguna media sosial
semakin terkait dengan
ketidakpercayaan r diri
penggunanya dengan bentuk
tubuh. Apalagi jika pengguna
itu terlibat dalam aktivitas
tertentu di media sosial,
seperti r melakukan
perbandingan penampilan
dengan orang lain (Anisa
Annan, 2019).

Body shame merupakan perasaan malu akan salah satu bentuk bagian tubuh ketika penilaian orang lain dan penilaian diri sendiri tidak sesuai dengan diri ideal yang diharapkan individu. Body shame terjadi ketika orang mengevaluasi bentuk tubuh kita. Komentar warganet lewat akun Instagram (a)carissa.putrie perihal bentuk hidung Dian yang seharusnya diperbaiki dengan operasi plastik merupakan konstruksi tidak realistis dari pengguna media sosial. Warganet terlanjur termakan 
gambaran tak realistis tentang seperti apa bentuk fisik seseorang.

\section{Make Moral Judgement}

(Keputusan Moral). Dalam teks beritanya

Nakita.grid.id

mengungkapkan bahwa menghina ternyata salah satu bentuk pelepasan psikologis bagi orang yang merasa tidak aman. Nakita.id menitir pernyataan yang dimuat Psychology Today bahwa upaya menjatuhkan seseorang secara verbal, dilansir Psychology Today, secara psikologis dapat diinterpretasikan sebagai pelampiasan keinginan untuk menurunkan status sosial sasaran komentar. Sebuah komentar menjatuhkan seringnya didorong oleh kemarahan terkait ketakutan pelakunya akan status sosialnya sendiri. Oleh karenanya Nakita.id memberikan penilaian moral atas kasus body shaming yang menimpa artis Dian Nitami dengan memuat komentar Kepala Peneliti Microsoft Research, Danah Boyd pada teks beritanya:

"Boyd merasa inilah waktunya kita semua merenungkan apa yang pernah kita ketik dengan jari-jari dan diunggah ke internet. Sebab konten itu akan menjadi konsumsi publik" (Anisa Annan, 2019).

Treatment Recommendation (Penyelesaian Masalah). Nakita.grid.id merekomendasikan agar warganet selalu mengingat etika bersosialisasi di media sosial.

Tabel 1

Perbandingan Frame Perbandingan Tempo.Co dan Nakita.Id

\begin{tabular}{|c|c|c|}
\hline $\begin{array}{l}\text { Elemen } \\
\text { Frame }\end{array}$ & Tempo.co & Nakita.grid.id \\
\hline Define Problem & Hukum & Moral \\
\hline \multirow[t]{2}{*}{ Diagnose Causes } & $\begin{array}{l}\text { Penyebab masalahnya adalah } \\
\text { pemilik akun Instagram } \\
\text { a,corri.putrie } \\
\text { Aktor pahlawan: Anjasmara, } \\
\text { suami Dian Nitami }\end{array}$ & $\begin{array}{l}\text { Penyebab masalah: } \\
\text { 1. Akun@corissa.putrie } \\
\text { 2. Para wanita pengguna } \\
\text { media social }\end{array}$ \\
\hline & & 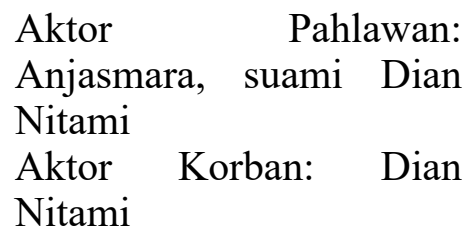 \\
\hline $\begin{array}{l}\text { Make Moral } \\
\text { Judgement }\end{array}$ & $\begin{array}{l}\text { Pelaku pelanggaran Undang- } \\
\text { Undang Informasi dan } \\
\text { Transaksi Elektronik (UU } \\
\text { ITE) atau Undang-Undang } \\
\text { nomor } 11 \text { tahun } 2008 \text { dapat } \\
\text { terancam hukuman penjara } \\
\text { selama enam tahun }\end{array}$ & $\begin{array}{l}\text { Inilah waktunya kita } \\
\text { semua merenungkan apa } \\
\text { yang pernah kita ketik } \\
\text { dengan jari-jari dan } \\
\text { diunggah ke internet. } \\
\text { Sebab konten itu akan } \\
\text { menjadi konsumsi publik }\end{array}$ \\
\hline $\begin{array}{l}\text { Treatment } \\
\text { Recommendation }\end{array}$ & $\begin{array}{l}\text { Tempo. } \\
\text { merekomendasikan }\end{array}$ & $\begin{array}{lr}\begin{array}{l}\text { Setiap warganet } \\
\text { mengingat }\end{array} & \text { selalu } \\
\text { etika }\end{array}$ \\
\hline
\end{tabular}




\begin{tabular}{|l|l|ll|}
\hline & $\begin{array}{l}\text { masyarakat lebih arif dan } \\
\text { bijaksana dalam bertutur kata } \\
\text { di sosial media, karena saat ini } \\
\text { sudah ada sanksi hukumnya. }\end{array}$ & sosial. & \\
\hline
\end{tabular}

Sumber: Olahan Peneliti

\section{SIMPULAN}

Media merupakan sarana bagi masyarakat dalam memahami berbagai realitas. Melalui konstruksi beritanya wartawan menampilkan sekaligus menempatkan peristiwa dalam konteks sosial tertentu di mana khalayak itu berada. Media di sini berupaya untuk menjaga nilai-nilai kelompok, dan melakukan kontrol agar nilai-nilai kelompok itu dijalankan, sehingga membentuk kenyataan apa yang layak, apa yang baik, apa yang sesuai, dan apa yang dipandang menyimpang.

\section{Daftar Pustaka}

Asep Saeful Muhtadi. 1999. Jurnalistik: Pendekatan Teori dan Praktik. Jakarta: Logos Wacana Ilmu.

Effendy Uchjana, O. 2013. Ilmu Komunikasi Teori dan Praktek. Bandung: Remaja Rosda Karya.

Eriyanto. 2012. Analisis Framing: Konstruksi, Ideologi dan Politik Media. Yogyakarta: Lkis Printing Cemerlang.

Hamad, I. 2004. Konstruksi Realitas Politik Dalam Media Massa. Jakarta: Granit.

Kriyantono, R. 2006. Teknik Praktis Riset Komunikasi. Jakarta: Kencana Prenanda Media Grup.

Salim, A. 2001. Teori Paradigma Penelitian Sosial.
Yogyakarta: Tiara Wacana.

\section{Sumber lain:}

Anisa Annan. (2019). Body Shaming Dian Nitami Karena Bentuk Hidung, Apa Benar Tidak Ideal. Diakses dari https://nakita.grid.id/read/0214 14326/body-shaming-diannitami-karena-bentuk-hidungapa-benar-tidak-ideal?page $=$ all

Anisa Annan. (2019). Dialami Dian Nitami, Survey Ungkap Body Shaming Dilakukan Oleh Sesama Perempuan. Diakses dari

https://nakita.grid.id/read/0214 13247/dialami-dian-nitamisurvei-ungkap-body-shamingdilakukan-oleh-sesamaperempuan?page $=$ all

Chairani, L. (2018). Body Shame dan Gangguan Makan. Buletin Psikologi, 26(1), 12-27. https://doi.org/10.22146/buleti npsikologi.27084

Daruwati, M. K. (2018). Artis Senior Dian Nitami Kena Hujat Warganet Karena Hidungnya, Begini Balasan Telaknya!. Diakses dari https://nakita.grid.id/read/0212 78176/artis-senior-dian-nitamikena-hujat-warganet-karenahidungnya-begini-balasantelaknya?page $=$ all

Diah Puspita Ningrum. (2018). Menolak Memaafkan, Anjasmara Minta Pembully Istri Lakukan Ini Agdar Tidak 
Dipidanakan. Diakses dari https://nakita.grid.id/read/0212 79206/menolak-memaafkananjasmara-minta-pembullyistrinya-lakukan-hal-ini-agartidak-dipidanakan?page $=$ all

Nurhayati, N. (2019,. Dilaporkan Anjasmara, Penghina Dian Nitami Terancam Dipenjara. Diakses dari https://seleb.tempo.co/read/116 1186/dilaporkan-anjasmarapenghina-dian-nitamiterancam-dipenjara

Pahlawani, P. A. (2018). Cuma Orang Cerdas Yang Tak Lakukan Body Shaming, Ini Alasannya! Idntimes.Com. Diakses dari https://www.idntimes.com/life/ inspiration/putri-aisya/alasantak-boleh-lakukan-bodyshaming-c1c2-1

Tarigan, M. (2018). Awas, Body Shaming Akibatkan Diare dan Sakit Kepala. Diakses dari https:/gaya.tempo.co/read/106 6928/awas-body-shamingakibatkan-diare-dan-sakitkepala/full\&view $=$ ok

Tarigan, M. (2018). Dian Nitami Alami Body Shaming, Apa Dampak Body Shaming?. Diakses dari https://gaya.tempo.co/read/116 0084/dian-nitami-alami-bodyshaming-apa-dampak-bodyshaming $/$ full\&view $=$ ok

Tarigan, M. (2018,). Istri Dihina, Intip Cara Anjasmara Bela Istri..

https://gaya.tempo.co/read/116 0030/istri-dihina-intip-caraanjasmara-bela-istri 